\title{
Family Medicine Residents' Experience During Early Phases of the COVID-19 Pandemic
}

\author{
Dean A. Seehusen, MD, MPH | Amanda Kost, MD, MEd | Wendy B. Barr, MD, MPH, MSCE | \\ Mary Theobald, MBA I Diane M. Harper, MD, MPH | Aimee R. Eden, PhD, MPH
}

PRiMER. 2021;5:18.

Published: 6/14/2021 | DOI: 10.22454/PRiMER.2021.909862

\section{Abstract}

Background and Objectives: Residents have been thrust onto the front lines of the US medical response to COVID-19. This study aimed to quantify and describe the experiences of family medicine residents nationally during the early phases of the pandemic. Specific areas of interest included training received and the residents' personal sense of safety. The purpose of this study was to look for differences among residents based on geographic location.

Method: This May 2020 survey was conducted by the Council of Academic Family Medicine Educational Research Alliance (CERA) of a random sample of 5,000 resident members of the American Academy of Family Physicians (AAFP).

Results: The overall response rate for the survey was $5.66 \%(283 / 5,000)$. More than $40 \%$ of residents reported having felt in moderate to significant personal danger during the COVID-19 pandemic. Fewer than $20 \%$ had been tested for COVID-19 themselves. Among all respondents, 176 (65.7\%) of the residents had provided direct patient care for COVID-19-positive patients. Most had been trained on personal protective equipment and the medical aspects of COVID-19, but $16.2 \%$ reported no training on how to care for COVID-19 patients. Minority residents, and residents in larger urban areas were less likely to receive timely training.

Conclusions: The COVID-19 pandemic has had a major impact on family medicine residents' medical education and their sense of safety. Regional variations in residents' educational experiences during the pandemic exist. Training prior to COVID-19 exposure was not universal. In our sample, minority residents were less likely to receive timely training than White residents.

\section{Introduction}

The COVID-19 pandemic reshaped health care delivery almost overnight. Because resident physicians provided a large proportion of direct patient care in many health systems, they faced unique burdens as the pandemic unfolded. ${ }^{1,2}$

Residency training structures can make rapid change difficult. Evolving information and misinformation, coupled with shortages of medical equipment created challenges and ethical dilemmas for trainees and 
educators. ${ }^{3-5}$ Programs struggled with protecting trainees from harm, preparing them to care for patients with COVID, and continuing their education. ${ }^{6}$ Many trainees lost valuable months of patient care interactions. ${ }^{7}$ Caring for patients without proven treatment options produced existential distress for residents and supervising physicians. ${ }^{6}$

The Council of Academic Family Medicine Educational Research Alliance (CERA) surveyed a national sample of family medicine residents to explore their experiences early in the pandemic.

\section{Methods}

This study was part of a CERA omnibus survey approved by the American Academy of Family Physicians (AAFP) Institutional Review Board and conducted in May 2020. CERA methodology has been previously described. ${ }^{8}$ A random sample of 5,000 resident members of the AAFP were sent email invitations with a link to the survey. Follow-up emails were sent on days 4 and 10.

We conducted statistical analysis with SPSS software (Version 25, IBM Corp., Armonk, NY). After initial descriptive statistics, we collapsed some categories due to underrepresentation in some groups, to allow bivariate analysis by $\chi^{2}$. For instance, some regions were combined. An example is the New England and Middle Atlantic regions, which we combined into one region titled "Northeast." We also performed multivariate analysis using logistic regression.

\section{Results}

The response rate was $5.66 \%$ (283/5000). Table 1 displays demographic data. Gender, training level, and state were known for all 5,000 residents. Respondents generally resembled the target population on these variables; postgraduate year-1 (PGY1) residents were underepresented, and PGY3s overrepresented. Women outnumbered men congruent with Association of American Medical Colleges data. ${ }^{9}$

Table 2 summarizes respondents' early pandemic experiences. Most (65.7\%) had provided direct care for COVID-19 patients. Most of these residents had received training, but $16.2 \%$ reported receiving no training on caring for COVID-19 patients. More than $40 \%$ reported feeling in moderate to significant personal danger.

National regions did not differ significantly in the distribution of gender, race, age, or program type (Table 3). The Northeast region had the smallest percentage of residents (39.5\%) receive training before exposure to a COVID-19-positive patient. This was not statistically significantly less than the West North Central region, where $62.1 \%$ of residents received training before seeing their first positive case $(P=.06)$, but it is a noteworthy difference. Comparing those same two regions on the amount of personal danger felt shows that $61.1 \%$ of residents in the Northeast felt moderate or significant fear for their personal safety, compared to $29.6 \%$ in the West North Central region $(P=.01)$.

Few residents (13\%) reported that their program did not allow them to see COVID-19 patients. Another $26 \%$ reported that caring for COVID-19 patients was strictly voluntary. Most respondents felt that the pandemic had a negative impact on their education.

Table 4 summarizes data for those residents who had cared for COVID-19-positive patients. More than half reported never having received training or only receiving training after exposure to their first positive patient. Over half reported having felt in moderate to significant personal danger.

Logistic regression modeling (Table 5) revealed that after controlling for program type, US versus international medical graduate status, age, postgraduate year level, region of the country, and gender, minority residents and residents practicing in larger urban areas were less likely to have received training before caring for their first 
COVID-19 positive patient.

A separate logistic regression model evaluated variables associated with moderate to significant fear of personal danger among those residents that had cared for COVID-19 patients. After controlling for multiple variables, the only factor associated with reduced fear was having received training before care for their first COVID-19 patient $(A O R=0.22,95 \% \mathrm{Cl}=0.13-0.57, P=.001)$.

\section{Conclusions}

A significant number of family medicine residents provided care for COVID-19 patients. We know from other reports that family medicine was part of the pandemic response in all patient care environments. ${ }^{10,11}$ This underscores the need for family medicine to maintain a broad-based educational curriculum.

For learners, the level of impact of the pandemic on their education has been immense. COVID-19 has had a formative impact on all current medical learners, with unpredictable long-term implications for this cohort that should be tracked. For residency programs, the pandemic presented a flood of novel challenges with no clear best response. ${ }^{12}$ More than $10 \%$ of programs did not allow residents to care for COVID-19 positive patients. It is possible that factors such as a lack of PPE were the rationale for such decisions. Additional research of the rationale behind these variations would likely reveal significant innovativeness. ${ }^{13}$

In mid-March 2020, the Accreditation Council for Graduate Medical Education established that residents should not take care of known or suspected COVID-19 positive patients unless provided with proper PPE and training. ${ }^{14}$ Our data suggest that this did not occur in a surprisingly high percentage of cases. Residents in larger cities may have been exposed to positive patients earlier, without enough time for proper training. Family medicine residents of color were less likely to receive proper training before being exposed COVID-19 positive patients. This finding was still highly statistically significant after controlling for numerous other variables. One possibility is that residents of color are more likely to train at institutions with fewer resources. ${ }^{15}$ However, systematic racism in medical education must be included as a possible factor. ${ }^{16}$

This study has some weaknesses. The response rate was low. Surveys are always subject to recall bias. It is also important to note that the data were collected during a brief period of time in May 2020. At this point in the pandemic, only some areas of the West Coast and New England had experienced intense waves of COVID-19 cases. Many other areas of the country had been relatively spared at that time. The same residents might answer some of these questions differently now.

The low response rate, while probably not surprising for resident research, is another clear weakness of this study. The respondents were also skewed towards upper-level residents. Given that PGY1s often perform a disproportionate amount of the direct patient interaction with hospitalized patients, the response rate among the most highly-involved residents is even lower and limits the generalizability of these findings.

Future research should evaluate the long-term psychological impact on learners who cared for COVID-19positive patients. Future investigation should also explore racial inequities in medical education, and approaches to eliminating those inequities. Systematic evaluation of programs' responses to the pandemic, and how those differences impacted educational outcomes could lead to a more uniform educational response in future disasters.

\section{Tables and Figures}


Table 1: Demographic Data of Respondents. Known Demographic Data of the Entire 5,000 Residents Sample Is Also Represented

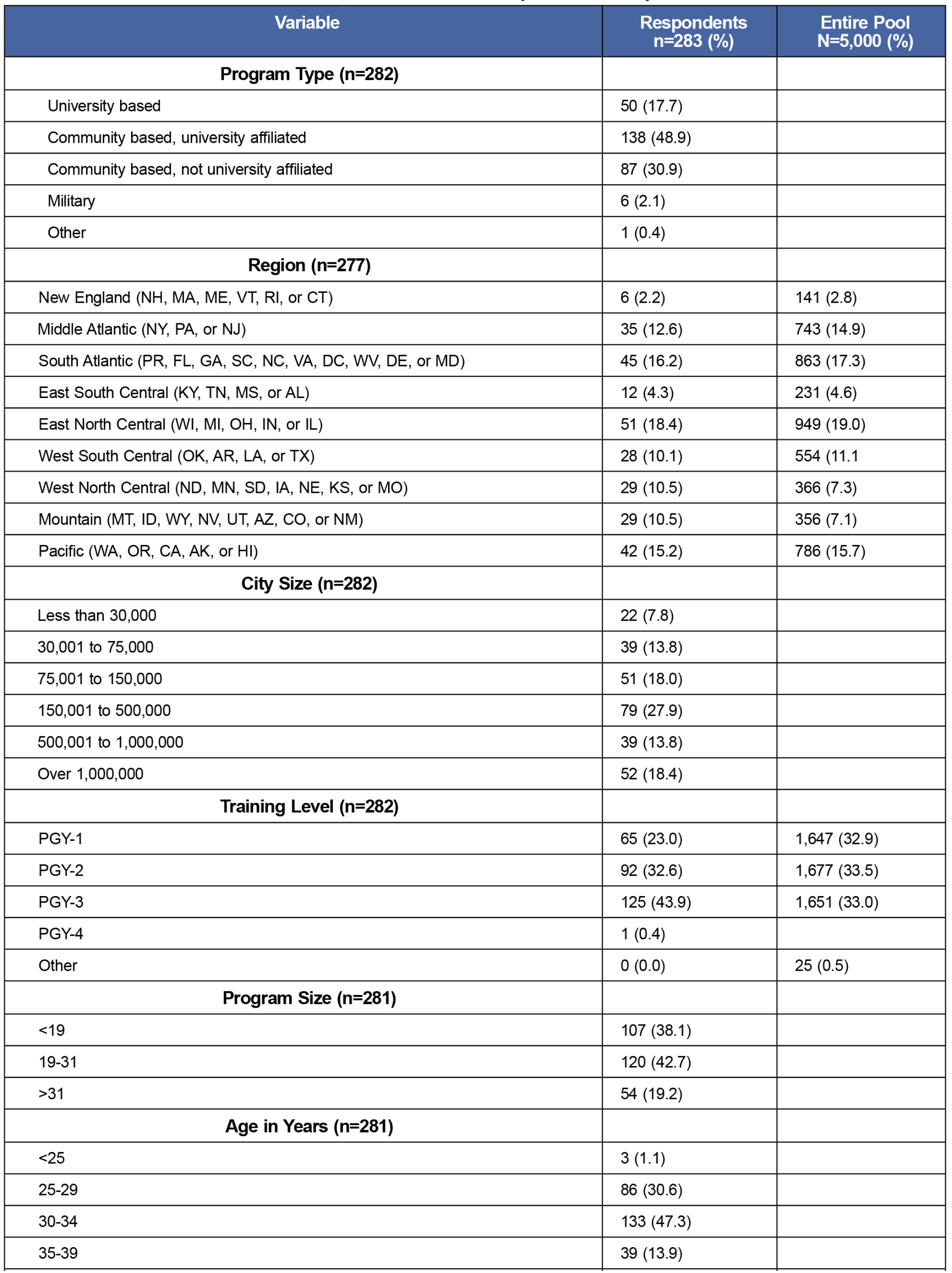




\begin{tabular}{|c|c|c|}
\hline $40-44$ & $8(2.8)$ & \\
\hline$>44$ & $12(4.3)$ & \\
\hline \multicolumn{3}{|c|}{ Marital Status $(n=280)$} \\
\hline Single & $96(34.3)$ & \\
\hline Married & $152(54.3)$ & \\
\hline Single with a long-term partner & $32(11.4)$ & \\
\hline \multicolumn{3}{|c|}{ Children $(n=282)$} \\
\hline No & $191(67.7)$ & \\
\hline Yes & $91(32.3)$ & \\
\hline \multicolumn{3}{|c|}{ Gender $(n=274)$} \\
\hline Male & $112(40.9)$ & $1,749(35.0)$ \\
\hline Female & $158(57.7)$ & $2,057(41.1)$ \\
\hline Transgender male & $1(0.4)$ & $1(0.0)$ \\
\hline Transgender female & $1(0.4)$ & $1(0.0)$ \\
\hline Preferred not to answer & $2(0.7)$ & $1,192(23.8)$ \\
\hline \multicolumn{3}{|c|}{ Race $(n=272)$} \\
\hline American Indian or Native Alaskan & $5(1.8)$ & \\
\hline Asian & $33(12.1)$ & \\
\hline African American & $23(8.5)$ & \\
\hline White & $186(68.4)$ & \\
\hline Other & $13(4.8)$ & \\
\hline Preferred not to answer & $12(4.4)$ & \\
\hline \multicolumn{3}{|c|}{ Medical School $(n=273)$} \\
\hline US medical graduate & $210(76.9)$ & \\
\hline International medical graduate & $63(23.1)$ & \\
\hline
\end{tabular}


Table 2: Resident Experiences During the Early Phases of the COVID-19 Pandemic

\begin{tabular}{|c|c|}
\hline Question and Responses for All Respondents (Total n=283) & $\mathrm{n}(\%)$ \\
\hline \multicolumn{2}{|l|}{ Have Cared for COVID-19-Positive Patients (n=268) } \\
\hline No & $92(34.3)$ \\
\hline Yes & $176(65.7)$ \\
\hline \multicolumn{2}{|l|}{ Impact of COVID-19 Pandemic on Medical Training ( $n=259)$} \\
\hline Completely, in a negative direction & $52(20.1)$ \\
\hline Moderately, in a negative direction & $121(46.7)$ \\
\hline Minimally, in a negative direction & $33(12.7)$ \\
\hline No impact & $9(3.5)$ \\
\hline Minimally, in a positive direction & $9(3.5)$ \\
\hline Moderately, in a positive direction & $32(12.4)$ \\
\hline Completely, in a positive direction & $3(1.2)$ \\
\hline \multicolumn{2}{|l|}{ Had Been Tested for COIVD-19 (n=262) } \\
\hline No & 211 (80.5) \\
\hline Yes & $51(19.5)$ \\
\hline \multicolumn{2}{|l|}{ Type of Training for Direct Care of Patients With COVID-19 (n=266) } \\
\hline No training on caring for patients with COVID-19 & $43(16.2)$ \\
\hline Training on PPE only & $30(11.3)$ \\
\hline Training on the medical aspects of COVID-19 only & $16(6.0)$ \\
\hline Training on both & $177(66.5)$ \\
\hline \multicolumn{2}{|l|}{$\begin{array}{l}\text { Program Expectations Regarding Residents Caring } \\
\text { for COVID-19-Positive Patients }(n=270)\end{array}$} \\
\hline Not allowed & $35(13.0)$ \\
\hline Strictly voluntary with no extra pay & $33(25.2)$ \\
\hline Strictly voluntary with extra pay & $3(1.1)$ \\
\hline Required with no extra pay & $195(72.2)$ \\
\hline Required with extra pay & $4(1.5)$ \\
\hline \multicolumn{2}{|l|}{ Extent of Personal Danger Felt During the COVID-19 Pandemic $(n=262)$} \\
\hline None & $19(7.3)$ \\
\hline Minimal & $126(48.1)$ \\
\hline Moderate & $82(31.3)$ \\
\hline Significant & 35 (13.4) \\
\hline
\end{tabular}


Table 3: Findings by Region of the United States

\begin{tabular}{|c|c|c|c|c|c|c|c|c|}
\hline $\begin{array}{l}\text { Regional Differences Among } \\
\text { Resident Who Had Cared } \\
\text { for COVID-19-Positive } \\
\text { Patients* (Total n=283) }\end{array}$ & NE & SA & SC & ENC & WNC & $\mathbf{M}$ & $\mathbf{P}$ & $\begin{array}{c}P \\
\text { Value }\end{array}$ \\
\hline $\begin{array}{l}\text { Residents at university-based or } \\
\text { university-affiliated programs }\end{array}$ & $65.9 \%$ & $66.7 \%$ & $60.8 \%$ & $75.0 \%$ & $89.7 \%$ & $58.6 \%$ & $59.5 \%$ & .09 \\
\hline International medical graduates & $26.3 \%$ & $14.0 \%$ & $40.8 \%$ & $35.9 \%$ & $10.3 \%$ & $3.6 \%$ & $16.7 \%$ & $<.01$ \\
\hline Female & $63.2 \%$ & $47.6 \%$ & $58.3 \%$ & $66.7 \%$ & $62.1 \%$ & $53.6 \%$ & $61.0 \%$ & .68 \\
\hline $\begin{array}{l}\text { Felt COVID-19 had negatively } \\
\text { impacted their medical training }\end{array}$ & $72.2 \%$ & $82.5 \%$ & $83.3 \%$ & $81.1 \%$ & $96.3 \%$ & $73.1 \%$ & $75.0 \%$ & .25 \\
\hline $\begin{array}{l}\text { Received training before contact with } \\
\text { their first COVID-19-positive patient }\end{array}$ & $39.5 \%$ & $51.2 \%$ & $54.2 \%$ & $50.0 \%$ & $62.1 \%$ & $44.4 \%$ & $42.9 \%$ & .57 \\
\hline
\end{tabular}

Regions:

NE: Northeast (NH, MA, ME, VT, RI, CT, NY, PA, or NJ)

SA: South Atlantic (PR, FL, GA, SC, NC, VA, DC, WV, DE, or MD)

SC: South Central (KY, TN, MS, AL, OK, AR, LA, or TX)

ENC: East North Central (WI, MI, OH, IN, or IL)

WNC: West North Central (ND, MN, SD, IA, NE, KS, or MO)

M: Mountain (MT, ID, WY, NV, UT, AZ, CO, or NM)

$\mathrm{P}$ : Pacific (WA, OR, CA, AK, or HI) 
Table 4: Characteristics of Family Medicine Residents Who Had Cared for COVID-19-Positive Patients

\begin{tabular}{|c|c|}
\hline Family Medicine Residents Who Had Cared for COVID-19-Pc & n (\%) \\
\hline \multicolumn{2}{|l|}{ Program Type $(n=176)$} \\
\hline University based or university affiliated & $116(65.9)$ \\
\hline Not university affiliated, military, or other & $60(34.1)$ \\
\hline \multicolumn{2}{|l|}{ Training Level $(n=176)$} \\
\hline PGY-1 & $40(22.7)$ \\
\hline PGY-2 & $64(36.4)$ \\
\hline PGY-3 or 4 & $72(40.9$ \\
\hline \multicolumn{2}{|l|}{ Gender $(n=173)$} \\
\hline Male & $74(42.8)$ \\
\hline Female & $99(57.2)$ \\
\hline \multicolumn{2}{|l|}{ Race $(n=166)$} \\
\hline White & $120(72.3)$ \\
\hline All minorities & $46(27.7)$ \\
\hline \multicolumn{2}{|l|}{ Region $(n=173)$} \\
\hline Northeast(NH, MA, ME, VT, RI, CT, NY, PA, or NJ) & $28(16.2)$ \\
\hline South Atlantic (PR, FL, GA, SC, NC, VA, DC, WV, DE, or MD) & $22(12.7)$ \\
\hline South Central (KY, TN, MS, AL, OK, AR, LA, or TX) & $29(16.8)$ \\
\hline East North Central (WI, MI, OH, IN, or IL) & $26(15.0)$ \\
\hline West North Central (ND, MN, SD, IA, NE, KS, or MO) & $18(10.4)$ \\
\hline Mountain (MT, ID, WY, NV, UT, AZ, CO, or NM) & $21(12.1)$ \\
\hline Pacific (WA, OR, CA, AK, or HI) & $29(16.8)$ \\
\hline \multicolumn{2}{|c|}{ Had Been Tested for COVID-19 ( $n=176)$} \\
\hline No & $131(76.2)$ \\
\hline Yes & $41(23.8)$ \\
\hline \multicolumn{2}{|c|}{ Impact of COVID-19 Pandemic on Medical Training ( $n=176)$} \\
\hline Negative & $132(78.1)$ \\
\hline Neutral or positive & $37(21.9)$ \\
\hline \multicolumn{2}{|c|}{ Extent of Personal Danger Felt During the COVID-19 Pandemic $(n=172)$} \\
\hline None or minimal & $80(46.5)$ \\
\hline Moderate or significant & $92(53.5)$ \\
\hline \multicolumn{2}{|c|}{ Type of Training for Direct Care of Patients With COVID-19 ( $n=157)$} \\
\hline Training on PPE only & $22(14.0)$ \\
\hline Training on the medical aspects of COVID-19 & $10(6.4)$ \\
\hline Training on both & $125(79.6)$ \\
\hline \multicolumn{2}{|l|}{ Timing of Training $(n=176)$} \\
\hline No training or only after first contact with first COVID-19-positive patient & $101(57.4)$ \\
\hline Training before contact with first COVID-19-positive patient & $75(42.6)$ \\
\hline
\end{tabular}


Table 5: Logistic Regression Model of Having Received Training Before Caring for First COVID-19-Positive Patient

\begin{tabular}{|l|c|c|c|}
\hline \multicolumn{1}{|c|}{ Variable } & AOR & $95 \%$ CI & $P$ Value \\
\hline Program type (university or university-affiliated versus all other) & 0.76 & $0.38-1.55$ & .46 \\
\hline Medical school (US versus international) & 0.86 & $0.39-1.93$ & .72 \\
\hline Race (all minorities versus White) & 0.41 & $0.19-0.91$ & .03 \\
\hline Age (30 years or older versus under 30 years) & 1.01 & $0.50-2.05$ & .97 \\
\hline PGY level & 0.89 & $0.58-1.36$ & .58 \\
\hline Gender (male versus female) & 1.04 & $0.53-2.02$ & .92 \\
\hline Region & 1.12 & $0.98-1.28$ & .11 \\
\hline City size (over 150,000) & 0.49 & $0.25-0.96$ & .04 \\
\hline
\end{tabular}

Abbreviation: AOR, adjusted odds ration, adjusted for other variables in the model.

\section{Corresponding Author}

Dean A. Seehusen, MD, MPH

Augusta University, 1120 15th St, AE 3046, Augusta, GA 30912. 706-723-4385.

dseehusen@msn.com

\section{Author Affiliations}

Dean A. Seehusen, MD, MPH - Department of Family Medicine, Augusta University, Augusta, GA

Amanda Kost, MD, MEd - Department of Family Medicine, University of Washington School of Medicine, Seattle, WA

Wendy B. Barr, MD, MPH, MSCE - Lawrence Family Medicine Residency, Lawrence, MA I and the Tufts University School of Medicine, Boston, MA

Mary Theobald, MBA - Society of Teachers of Family Medicine, Leawood, KS

Diane M. Harper, MD, MPH - University of Michigan Medical School, Ann Arbor, MI

Aimee R. Eden, PhD, MPH - American Board of Family Medicine, Lexington, KY

\section{References}

1. Nasca TJ. ACGME's early adaptation to the COVID-19 pandemic: principles and lessons learned. J Grad Med Educ. 2020;12(3):375-378. doi:10.4300/JGME-D-20-00302.1

2. Rakowsky S, Flashner BM, Doolin J, Reese Z, Shpilsky J, Yang S, Smith CC, Graham K. Five questions for residency leadership in the time of COVID-19: reflections of chief medical residents from an internal medicine program. Acad Med. 2020 Apr 13: Published Online ahead of print. doi:10.1097/ACM.0000000000003419.

3. Grimm A. Hospital experiences responding to the COVID-19 pandemic: results of a national pulse survey March 23-27, 2020. Accessed July 1, 2020. https://www.oig.hhs.gov/oei/reports/oei-06-20-00300.pdf.

4. Reddin E. Rush to publish risks undermining COVID-19 research. Inside Higher Ed. June 8, 2020. Accessed July 1, 2020. https://www.insidehighered.com/news/2020/06/08/fast-pace-scientificpublishing-covid-comes-problems.

5. ACGME Statement on the Shortage of Personal Protective Equipment (PPE). News Relesase. ACGME 
News. Published April 5, 2020. Updated July 30, 2020. Accessed July 1, 2020.https://www.acgme.org /Newsroom/Newsroom-Details/ArticleID/10186/ACGME-Statement-on-the-Shortage-of-PersonalProtective-Equipment-PPE.

6. Berookhim J, Correa A, Tamis-Holland JE. Notes from the Eye of the Storm: Trainees at the Frontlines of the COVID-19 Pandemic. J Am Coll Cardiol. 2020:S0735-1097(20)35309-2. Published online ahead of print. doi:10.1016/j.jacc.2020.05.021.

7. Teaching Hospitals, Teaching Physicians and Medical Residents: CMS Flexibilities to Fight COVID-1. Delray Beach, FL: mTelehealth.; 2020. https://www.cms.gov/files/document/covid-teachinghospitals.pdf. Accessed June 26, 2020.

8. Seehusen DA, Mainous AG III, Chessman AW. Creating a centralized infrastructure to facilitate medical education research. Ann Fam Med. 2018;16(3):257-260. doi:10.1370/afm.2228

9. Report on Residents. Association of American Medical Colleges. https://www.aamc.org/data-reports /students-residents/interactive-data/report-residents/2019/table-b3-number-active-residents-typemedical-school-gme-specialty-and-sex. Accessed June 26, 2020.

10. Chen FM. COVID-19 and family doctors. Fam Med. 2020;52(4):306-307. doi:10.22454/FamMed.2020.515917

11. Family Medicine Resident Physicians on the Frontline of COVID-19. Michigan Academy of Family Physicians. Published April 7, 2020. Accessed July 3, 2020. https://www.mafp.com/news/familymedicine-resident-physicians-on-the-frontline-of-covid-19.

12. Ferrel MN, Ryan JJ. The impact of COVID-19 on medical education. Cureus. 2020;12(3):e7492. doi:10.7759/cureus.7492

13. Dedeilia A, Sotiropoulos MG, Hanrahan JG, Janga D, Dedeilias P, Sideris M. Medical and surgical education challenges and innovations in the COVID-19 era: a systematic review. In Vivo. 2020;34(3) (suppl):1603-1611. doi:10.21873/invivo.11950

14. Special Edition e-Communication - March 16, 2020. Accreditation Council for Graduate Medical Education. Published March 15, 2020. Accessed June 25, 2020. https://acgme.org/Newsroom /Blog/Details/ArticlelD/10120/Special-Edition-e-Communication-March-16-2020.

15. Rosenthal B, Goldstein J, Otterman S, Fink S. Why Surviving the Virus Might Come Down to Which Hospital Admits You. The New York Times. July 2, 2020. Accessed July 8, 2020. https://www.nytimes.com/2020/07/01/nyregion/Coronavirus-hospitals.html?searchResultPosition=1.

16. Ko M. Racism in my medical education. Health Aff (Millwood). 2020;39(6):1087-1091. Review. doi:10.1377/hlthaff.2019.00743

Copyright $(2021$ by the Society of Teachers of Family Medicine 